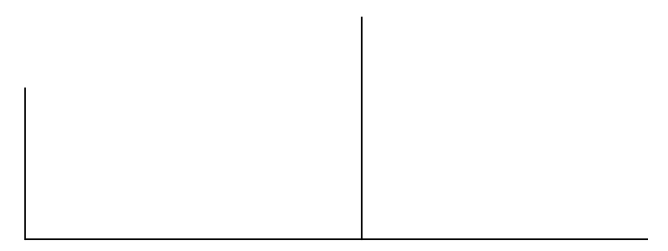

Rev. Latinoam. Psicop. Fund. II. 4, 164-175

\title{
A endogenidade como origem da melancolia e do tipo melancólico*1
}

H. Tellenbach

\begin{abstract}
A psiquiatria distingue três grupos de transtornos: somatógenos, psicógenos e endógenos. Evidentemente, esta distinção repousa sobre uma delimitação de três campos causais. Os dois primeiros podem ser chamados soma e psique. O terceiro, até agora não tem nome. Por razões lógicas deveríamos denominar endon o campo causal das alterações endógenas. "Endógeno" quer dizer "nascido dentro" (ou seja, na casa). Endon designa, por conseguinte, uma origem e, neste sentido, também uma procedência.

$\mathrm{O}$ fato de a psiquiatria não ter resolvido nem caracterizado a região da qual provém as alterações endógenas, alude a uma certa insegurança na concepção desse terceiro campo causal. O conceito de endógeno, assim como a diferenciação entre endógeno e exógeno, foram introduzidos em psiquiatria por Moebius em $1892^{2}$. Endogenidade é, para esse autor, um predicado do degenerativo e o formula assim: "Só sob a condição de que seja degenerado é
\end{abstract}

* Tradução de Fabiana Gradela Casarini e revisão técnica do Prof. Dr. Mário Eduardo Costa Pereira (ambos do Laboratório de Psicopatologia Fundamental-UNICAMP).

1. H. Tellenbach. "La endogenidad como origen de la melancolía y del tipo melancólico". In. Estudios sobre la patogénesis de las perturbaciones psíquicas. México: Fondo de Cultura Económica, 1969, pp. 29-44.

2. Cf. A. Mechler. “Degeneration und Endogenität”, Nervenarzt, 34, 1963. 


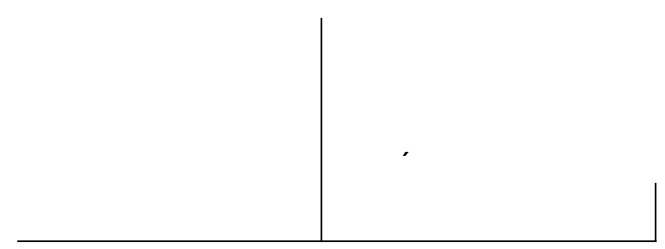

possível que alguém sofra de uma enfermidade endógena”. Com isso, coloca o endógeno desde o princípio em proximidade imediata do somático. Estreitamente ligado ao conceito de “disposição”, o endógeno aparece como uma região etiológica pertencente ao território do soma, mas não definível mais do que isso, e à qual são reduzidas aquelas alterações psíquicas chamativas que se denominam psicoses endógenas. A psiquiatria tem visto claramente o peculiar e inequívoco de tais psicoses, e as tem designado acertadamente com o termo de endógenas, mas em seguida tem "somatizado” de forma demasiado irrefletida o endógeno.

$\mathrm{Na}$ realidade, considera-se o endógeno como algo somatógeno, entretanto ainda não comprovado e, no curso do tempo, espera-se poder esclarecer o campo obscuro de sua procedência como um campo causal somático. Mas, até então, o endógeno continuará absolutamente como criptógeno. Portanto, no fundo, “endógeno” é um conceito negativo.

Em contraposição ao anterior, tentaremos revelar aqui o conteúdo positivo definível do endon e do endógeno. Quando J. Wyrsch, ao final de sua contribuição à história das psicoses endógenas, coloca a pergunta se as diversas formas fenomênicas do ser-do-homem "são reunidas em um todo por alguma instância"3, e quando a seguir interroga se as psicoses endógenas estariam aí incluídas, nós respondemos a essas interrogações: que com o termo endon compreendemos a instância espontânea e original que se manifesta em certas formas fundamentais do ser-do-homem, e que essas formas fenomênicas - tanto em momentos de saúde como, e com maior razão, em momentos de psicose - são o que queremos designar como endógeno. Esta "novidade enigmática da endogenidade”" tão inconfundível em seus modos de manifestação psicóticos, alude na totalidade das alterações psíquicas a uma dimensão tão ampla de procedência, que dita dimensão tem de considerá-la como algo completamente original. H. Kunz ${ }^{5}$ fala dessa originalidade como "uma endogenidade radical e constitutiva do ser-do-homem como tal”. Kunz a entende como o "caráter acontecitivo interior" que se representa, antes de tudo, nos “processos de maturação tão dificilmente inteligíveis”. Refere-se com isso ao desdobramento de si mesmo, implícito, involuntário e subtraído à própria disponibilidade.

Mas endógeno é também o involuntário que caracteriza o ser-do-homem em sua singularidade, que mantém sua própria identidade no decurso temporal: em seu

3. J. Wyrsch. Zur Geschichte und Deutung der endogenen Psychosen. Stuttgart: Thieme Verlag, 1956, p. 90.

4. W. von Bayer. “Über Freiheit und Verantwortlichkeit von Geisteskranken”, Nervenarzt, 25, 265, 1954.

5. Über den Sinn und die Grenzen des psychologischen Erkennens. Stuttgart: Klett, 1957, p. 89. 


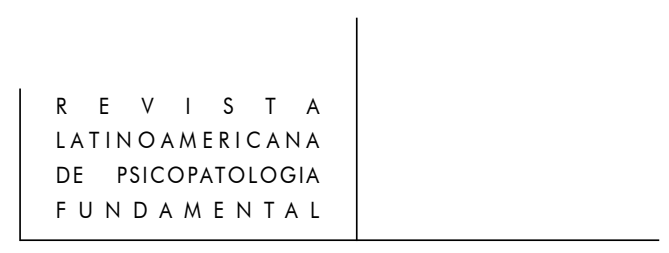

sexo, em sua raça, em suas predisposições e dotes transmitidos por herança, em suas atitudes e formas de manifestação típicas. Aqui pertencem também os tipos da constituição corporal, as particularidades e qualidades da inteligência, as índoles do temperamento afetivo fundamental: enfim, a estruturação e cunhagem antecipadas da individualidade, a qual mantém sua forma específica por meio de formações e transformações no decorrer do tempo. Podemos dizer que endógeno é tudo o que no acontecer vital do homem se realiza sempre novamente como unidade da forma fundamental.

Chamamos endon ao que constantemente manifesta essa originalidade em tais fenômenos do endógeno. Endon não é, por conseguinte, o impessoal do biológico, nem tampouco o pessoal no sentido do reino das decisões existenciais. O endon precede a tudo isso, porque é o que o faz possível e o cunha e está depois de tudo isso, porque pode ser estimulado e configurado tanto desde a esfera espiritualpessoal como ao próprio ao mundano. Quando Goethe fala do suceder como formação e transformação de naturezas orgânicas em contato com o mundano, inclui também a possibilidade de que o original que se desdobra nos fenômenos endógenos, e que chamamos endon, pode ser ameaçado e perturbado, pode ser retirado de seu caminho e finalmente transformado. Uma ameaça tal do endon ao ser-do-homem, tipicamente estruturado, impõe-lhe modos do existir contrários à sua estrutura, que todavia não pode evitar. Nós concebemos as psicoses endógenas como uma forma de exteriorização do endon deste modo ameaçado, perturbado e finalmente transformado.

Não é fácil esclarecer o íntimo contexto fenomênico do endon e da endogenidade. Seguramente representa uma modificação especial da relação fundamental, entelequial, aristotélica, da aparição de todos os seres no mundo através de manifestações. Maior ainda parece-me a proximidade com o conceito das idéias que tinha Goethe 6 , o filósofo da natureza, ou seja, a idéia como aquilo que "configura desde o interior”, e que expressou da maneira mais clara no célebre verso de suas "Palavras originárias órficas": "Forma cunhada, que vivendo se desenvolve...” Por isso é a maturação uma imagem tão clara de uma endogenidade normativa considerada positivamente: a maturação, na qual o indivíduo permanece ele mesmo e, todavia, se torna outro de uma maneira tão peculiar, é um processo impressionante de transformação endógena normativa. Não é certamente por casualidade que as modificações psicóticas do endógeno ocorram tão freqüentemente nas diversas etapas de maturação.

Quando perguntamos pelas modificações do endon que se manifestam nas psicoses endógenas, é necessário recordar que temos designado o endon como $a$

6. “Anschauende Urteilskraft”, T. XIII. Hamburgo: Chr. Wegner, 1955. 


\section{CLÁSSICOS DA \\ PSICOPATOLOGIA}

forma fundamental do suceder vital. A lei formal deste suceder se exterioriza, antes de tudo, em ritmos elementares que, por sua vez, ocorrem no ritmo circadiano e na periodicidade do ciclo feminino. Caráter rítmico mostra também as oscilações da capacidade de trabalho ao longo do transcorrer do dia ou do ano, assim como as oscilações do temperamento afetivo ${ }^{7}$ e dos impulsos ${ }^{8}$. Nos fenômenos da apetência, do desejo de alimento, de líquido e da satisfação sexual se vêem da mesma forma propriedades pelo menos aparentadas com o ritmo. $\mathrm{O}$ ato sexual como tal é também uma manifestação múltipla do rítmico.

Todos esses ritmos mostram alterações acentuadas nas modificações psicóticas. Novos ritmos patológicos se revelam no caráter cíclico das fases depressivas ou maníacas; na configuração evolutiva das oscilações maníaco-melancólicas que em ocasiões se registram ainda várias vezes ao dia; na periodicidade das catatonias. Também nas oscilações melancólicas diurnas se faz patente esse ritmo patológico novo do suceder vital, que modifica radicalmente a periodicidade normal do temperamento afetivo fundamental e dos impulsos. Entre as trocas da ordem do suceder contamos também a preferência que acusam as ciclotimias a manifestarse no começo e no fim do ano, sem esquecer a tendência que aparece durante o ciclo mensal feminino a estados distímicos vitais abortivos.

Junto ao momento do rítmico e de suas modificações patológicas das psicoses endógenas, pode se mencionar no caráter acontecitivo do ser-do-homem um segundo fenômeno: o modo em que o próprio acontecer é movido, sua kinesis. Inclusive em tempos de saúde, não é uniforme a corrente deste suceder. Na vigília, e sobretudo no estado de disposição, se dão acelerações, enquanto na fadiga e no dormir surgem atrasos. O movimento vital acontece mais lentamente na doença, e isto é importante para o papel das afeç̧ões no pré-campo das melancolias. Na tristeza profunda, o suceder fundamental flui mais lentamente, enquanto em todos os estados felizes este se dá mais rapidamente, sobretudo nos momentos de procriação e de criação espiritual. Na melancolia, esse fluir das kinesis está modificado em diversos sentidos, com o qual a tendência geral à demora chega até o estancamento, até a "inibição do movimento vital básico". Esse estancamento aparece talvez com maior clareza na permanência da insônia e da angústia e tristeza, ou do não-poder-mais-estar-triste, no sentido de W. Schulte ${ }^{10}$. Mas estancamento

7. S.W. Engel. “Über den Ausdruck der cyclothymen Depression”, Arch. Psychiat. Nervenkr., 185, 511, 1950

8. H. Hammp. "Die tagesrhythmischen Schwankungen der Stimmung und des Antriebs beim gesunden Menschen”, Arch. Psychiat. Nervenkr., 201, 355, 1961.

9. V.E. von Gebsattel. Prolegomena zu einer medizinischen Anthropologie. Berlim-GotingamHeidelberg: Springer, 1954.

10. Nervenarzt, 37, 203, 1966. 


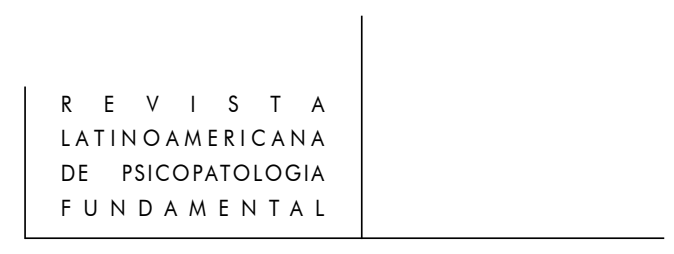

é também a monotonia de uma agitação, a "excitação angustiante insone prolongada durante meses" ${ }^{11}$, no quadro da chamada depressão queixosa. De maneira unívoca aparece a modificação qualitativa das kinesis endógena, certamente nos estupores, assim como igualmente no acelerado fluir da excitação maníaca ou catatônica.

Deve-se chamar enfaticamente a atenção para o fato de que em todos estes processos endógenos - tanto os normais como os modificados - o homem nunca aparece em sua realidade objetiva pura, nem em sua própria subjetividade. Sonho e vigília, comer e beber, criar e procriar: todos estes atos têm naturalmente um aspecto somático e um aspecto psíquico, dos quais, todavia, nunca se compreende mais do que uma única faceta. Por mais constitutivas que para certos métodos de nossa investigação sejam as distinções tais como interior e exterior, sujeito e objeto, físico e psíquico, a consideração dos fenômenos nos quais se desdobra o endon em manifestações endógenas nos conduz, apesar de tudo, a um nível que é transubjetivo em vez de transobjetivo, meta-somático ao mesmo tempo que metapsíquico. Isto vale, sobretudo, para as formas da endogenidade psicótica. Em nenhuma outra parte isto se mostra tão claramente como na terceira característica, a saber: naquele peculiar caráter global com o qual se apresentam as manifestações das psicoses endógenas. Em todos os estados acentuados é sempre a forma existencial própria, o ser-do-homem in toto, o que se modifica. Onde quer que sejam vistos quadros completos de psicoses endógenas, estes mostram uma surpreendente conformidade de comportamento e de expressão, na qual as diferenças pessoais parecem como borradas. Mas também quando uma psicose endógena se exterioriza alguma vez em forma "monossintomática", falamos injustamente de "sintomas" e não, o que seria melhor, de "fenômenos". Sintoma remete sempre a algo particular, a um campo alterado circunscrito. Somente o "complexo sintomático" representa o morbus como um todo. Por outro lado, a interpretação fenomenológica de uma psicose endógena mostra com claridade que todo fenômeno isolado - por exemplo, o de uma melancolia - é sempre representativo da melancolia como modificação global do ser-do-homem. No caso da esquizofrenia, Von Bayer ${ }^{12}$ fez ver como em todos os "sintomas" paranóides se encontra a mesma estrutura destrutiva específica da capacidade de encontro com outros homens. O impulso que desenvolve as síndromes das psicoses endógenas em sua especificidade global, não pode derivar unicamente da dimensão particular do orgânico ou do psíquico. A dimensão de sua procedência deve ser de uma generalidade tal que possa fazer nascer de si o inteligível em forma de fenômenos marcados, mas brotando todos eles de uma raiz comum. Esta raiz é o

11. W. Janzarik. Dynamische Grundkonstellation in endogenen Psychosen. Berlim: Springer, 1959, p. 31.

12. W. von Baeyer. Der Begriff der Begegnung in der Psychiatrie, Nervenarzt, 26, 369, 1955. 
endon, cujas emissões mostram tanto mais claramente as aparências do global e o conforme, quanto mais radical é a modificação patológica.

Além das variações mórbidas do rítmico, da modificada kinesis da corrente do suceder e do fenômeno do global, apresenta-se a quarta característica de toda alteração endógena: o aparecimento da psicose em pontos relevantes da maturação. Pense-se nas hebefrenias, nas psicoses de involução e nas psicoses pré-senis. Os aspectos biológicos e psicológicos sozinhos não permitem uma compreensão exaustiva. Quem olha a puberdade unicamente - ou apenas decisivamente - desde sua relação com as glândulas endócrinas, não atenta para a questão relativa à origem dos estímulos das glândulas internas. As características da maturação biológica e psicológica devem sua procedência, um último caso, à instância metabiológica e metapsicológica do endon. Com razão H. J. Weitbrecht ${ }^{13}$ considera que as "mudanças endógenas" são a expressão de uma "entelequia do desenvolvimento da personalidade".

As modificações psicóticas, que começam num tempo com tais fases de maturação sempre críticas, referem-se sempre ao homem em sua totalidade. J. Zutt ${ }^{14}$ fala de uma "mudança do ser condicionado por leis supra-individuais". Uma fase tal da maturação não está dada somente na puberdade. A fenomenologia das idades da vida - como a esboçamos em outro lugar (1961) - pode demonstrar que à maturação do desenlace pubescente se segue uma maturação da condensação involutiva, na qual deve ter origem uma nova intensidade e profundidade do humano. Em último caso, um envelhecer feliz é mais um amadurecimento do que um enfraquecimento. Certo que a maturação atrofiada ou retraída que está no limiar da senilidade se caracteriza por formas regressivas do corpóreo, mas seguramente também por uma possibilidade "meta-orgânica" da maturação espiritual posterior. Aqui deve se realizar sobretudo o que R. Guardini ${ }^{15}$ chamou a "disposição cada vez mais franca àquilo que deve ser", ou seja, a disposição à morte, o "paradigma da endogenidade"16. Estes passos maturativos podem ter êxito, e o conseguem na maioria das vezes. As psicoses que se inserem nestas transições representam uma das várias possibilidades de fracasso de tais passos maturativos, fracasso no sentido de um suceder endógeno aberrante, no qual o realizado biologicamente, de certo modo, não é aceito ou "referendado" pelo pessoal.

Devemos contentar-nos com estes escassos esboços e mencionar somente uma quinta e última característica da endogenidade das psicoses, mas sem explicála. Mencionamos a reversibilidade espontânea, muitas vezes tão impressionante na

13. Beiträge zur Religionspychopathologie. Willsbach y Heidelberg: Scherer, 1948.

14. Das Schizophrenieproblem. Nosologische Hypothesen, Klin. Wschr., 34, 679, 1956.

15. Die Lebensalter. Wurzburgo: Werkbund Verlag, 1959.

16. H. Kunz. Op. cit. 


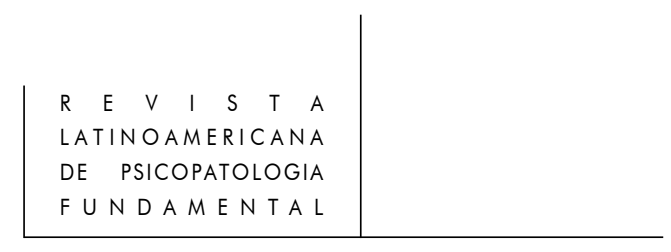

etapa pré-terapêutica. Essa reversibilidade é tão evidente nas psicoses fásicas, no sentido de $\mathrm{H}$. Bürger-Prinz ${ }^{17}$, quanto duvidosa nas esquizofrenias que entram em remissão sem deixar defeito. Todavia, também nestas últimas se têm observado remissões espontâneas, até em asilados de longos anos. Este problema tem sido tratado ultimamente de forma detalhada por Chr. Müller ${ }^{18}$. A nova revisão psiquiátrico-social da terapia das psicoses endógenas iluminará com outra luz mais de um aspecto.

Seria desejável que estas indicações sobre as características da modificação qualitativa do endon nas psicoses endógenas pudessem demonstrar que é possível e frutífero substituir a identificação puramente negativa do endógeno com o criptógeno, por uma definição baseada em características, na qual o endon se deixa delimitar positivamente como um terceiro campo causal. O endon se manifesta psíquica e fisicamente. Em sua modificação, troca o que abrangemos com os conceitos limítrofes de "psique" e "soma”. As alterações somáticas e psíquicas são imediatamente derivadas desta modificação originária. Se alguma vez se conseguir comprovar achados somáticos nas psicoses endógenas, os mesmos serão compreensíveis, secundariamente, como efeitos de uma modificação endótica, de modo completamente análogo, por exemplo, ao descobrimento anatômico de uma enfermidade sistematizada heredodegenerativa, descobrimento que de modo algum é primário, pois é o resultado de uma disontogênese produzida endogenicamente. As psicoses, as melancolias e as esquizofrenias endógenas não serão somatoses nem mesmo no caso de se descubrir a correlação somática das alterações psíquicas, e tampouco serão psicoses psicogênicas nem mesmo quando se puder realmente evidenciar o caráter patogênico de determinadas constelações vivenciais ou ambientais. Isto há de ser mantido firmemente com todas as suas conseqüências na interpretação da eficácia dos procedimentos somato e psicoterapêuticos.

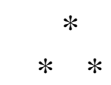

Há muito tempo a investigação tende a um aspecto que até agora excluímos, e com o qual a psiquiatria tem relacionado por vezes o problema da endogenidade. É o aspecto da transmissão hereditária de disposições patogênicas. A clínica vê a herança ligada aos genes, cujo princípio determinante de psicose passa a formar parte do somático e se atualiza como somatose nas psicoses endógenas. Certamente esta teoria é tão pouco demonstrável como aquela outra que atribui um papel etiológico decisivo às condições do mundo circundante. Além destas duas teorias,

17. Forum der Psychiatrie. T. II. Stuttgart: Enke, 1961.

18. Über das Senium der Schizophrenen. Basilea: Karger, 1959. 


\section{CLÁSSICOS DA}

PSICOPATOLOGIA

que hoje já não se pode manter num contrastante "aut-aut", senão melhor num articulante "et-et", aqui nos atemos somente àquilo que se mostra: o fato de que, no acúmulo familiar de doenças - especialmente em gêmeos univitelinos -, a conexão vital como propensão a modificações do endógeno é mais freqüente do que habitual. $\mathrm{O}$ endon está inclinado, tanto com respeito à sua extensão no fluxo do acontecer como às modalidades de seu desdobramento, a desviar-se de ordenamentos a cuja duração estão ligadas as formas fenomênicas normativas do ser espiritual-anímico. Esta tendência à transformação em melancolia é a que herdamos.

Tal comprovação geral poderia conduzir à hipótese errada de que tal tendência à modificação é algo isolável, e em tal qualidade, passível de se herdar. Uma idéia semelhante não faria justiça à ampla significação da endogenidade, que plasma ao homem desde o princípio. Dissemos antes que também é endógeno o que caracteriza o ser-do-homem como indivíduo: os típicos dotes, atitudes e formas de exteriorização, os temperamentos afetivos fundamentais e as cunhagens de lados decisivos na relação da personalidade com o mundo, que se mantêm firmemente em sua especificidade por meio das formações e transformações da pessoa. Em todos os pacientes que uma vez sofreram de depressão - e excluímos aqui conscientemente os doentes com fases maníacas - voltamos a encontrar sempre as mesmas e constantes características essenciais; poderíamos então supor que são formações específicas da endogenidade, e perguntamos se a elas corresponde um papel decisivo na patogênese das melancolias. Tais características constantes $e$ essenciais encontram-se de fato em todos os melancólicos, e justamente de um modo tão evidente que vemo-nos necessitados a falar de um tipo melancólico.

Antes de começar a explicar estas características, queremos chamar a atenção sobre para o fato de que não vamos conduzir aquele plano de reflexões sobre o qual tem sido desenvolvidas até agora as tipologias. Não tentamos, por conseguinte, nem uma tipologia constitucional, como a traçou, por exemplo, E. Kretschmer ${ }^{19}$, nem uma exposição como a que K. Schneider ${ }^{20}$ tem empreendido para caracterizar a personalidade anormal. Todas estas tipologias são, em sua conjunção com problemas da nosologia, predominantemente concepções estáticas que têm partido da consideração de um tipo como possível condição de um contexto patogenético. Outra coisa são as tipificações de F. Mauz ${ }^{21}$, que devido a sua vinculação com momentos do temporal têm uma afinidade muito maior com problemas da patogênese. Aqui se percebe a proximidade àquela classe de tipologia exposta por

19. Körperbau und Charakter. Berlim: Springer, 1955.

20. Die psychopathischen Persönlichkeiten, 9 ed. Viena: F. Deuticke, 1950.

21. Die Prognostik der endogenen Psychosen. Leipzig: Thieme, 1930. 


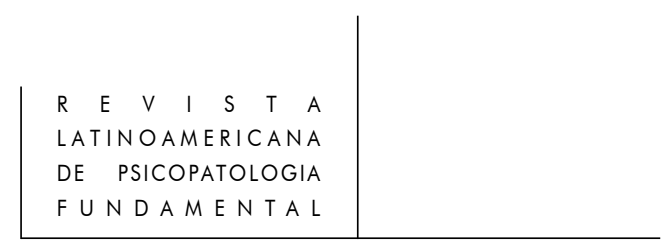

Kretschmer em seu Delírio sensitivo-paranóide ${ }^{22}$, ao que nosso procedimento deve impulsos decisivos. Nesta notabilíssima obra, Kretschmer liberou-se por completo de toda predestinação tipológica-constitucional em favor do princípio de uma reatividade caracterológica, especialmente sensitiva, que em suas respostas a vivências típicas, ou seja, a vivências de insuficiência vergonhosa e humilhante e a determinados fatos de um ambiente rigoroso, pode produzir e tematizar um delírio. A diferença da tipologia constitucional, que como momento patogenético conhece no auge um "autodesenvolvimento" (por exemplo, personalidades com predisposição ciclóide), Kretschmer vê em seu delírio sensitivo-paranóide a "única possibilidade de compreensão" de tais gêneses do delírio em um mútuo "condicionar-se de dinâmicas endógenas e psico-reativas". Com isso, descobriu um plano que nasce exatamente entre as premissas etiológicas alternantes, até agora tão estéreis, de uma endogenidade e de uma compreensão psicológica puras. O que pensamos quando falamos de "tipo" não é, por conseguinte, o resultado de medições, nem tampouco de um esquema teórico - por exemplo, caracterológico -, mas unicamente da intuição imediata. Obtemos traços essenciais do tipo melancólico não por meio da análise de propriedades e de sua estruturação sistemática, mas pelas experiências no encontro com aqueles que já foram melancólicos. Os traços fundamentais que apreendemos assim, em uma visão que vai se concretizando constantemente, são de natureza estrutural, enquanto determinados modos do ser estão aí pré-desenhados em forma definitiva. Isto se refere às fisionomias do vivenciado, moldadas desde o começo por estruturas constitutivas especiais; isso se estende aos modos de serativo, aos modos do trato inter-humano e também à relação consigo mesmo. Podemos caracterizar com toda clareza uma destas estruturas decisivas do tipo melancólico, que sempre é comprovável, quaisquer que sejam os outros elementos que compõem a personalidade, dizendo que está em determinada relação com a ordem, na qual chamados "ordenalidade" ${ }^{23}$. Quando falamos de ordem, o fazemos no sentido completamente simples e cotidiano de um afinamento regulado das relações essenciais de uma pessoa. Com "ordenalidade” pensamos primeiro em uma acentuada versão desta ordem, como a encontramos em muitas pessoas e também naquelas que nunca foram melancólicas. Por isso não compreendemos sob esta "ordenalidade" nenhuma característica de anormalidade. Veremos mais adiante porque o conceito de anormalidade não é critério de importância no plano de nossa investigação.

22. E. Kretschmer. Der sensitive Beziehungswahn. Berlim: Springer, 1950.

23. Optou-se por esse neologismo em consonância com “ordenalidad”, termo criado por LópezIbor para traduzir para o espanhol a palavra alemã Ordentlichkeit. (N. da T.) 


\section{CLÁSSICOS DA}

PSICOPATOLOGIA

Quando observamos a vida profissional do tipo melancólico, vêmo-la caracterizada por aplicação, escrupulosidade, consciência do dever e formalidade. A exigência do próprio rendimento é, sem exceção, muito viva. O trabalho é sempre uma "tarefa" que deve ser cumprida. Tem uma predileção pelo planejado, e sempre existe repulsão frente à improvisação. Realiza o planejado com a maior meticulosidade possível. As donas de casa esforçam-se pela limpeza mais escrupulosa; pode-se "comer no chão". Toda atividade - importante ou insignificante - é executada com igual intensidade. Reconhece-se aqui, e esta é a diferença decisiva com respeito à "ordenalidade" de tipo médio, um traço de rigidez, um estar fixado em e um ser fixado por uma ordem. Falta a elasticidade da livre disposição sobre aquilo que se realiza no trabalho: combinar com perspectiva o menos importante em contraste com o mais importante, fazer algo "com a mão esquerda" enquanto a direita executa o decisivo. O essencial está na própria atividade, e não em ser ativo, em cuja condição indispensável pertence também o momento diastólico, a "pausa produtiva". Entretanto, a atividade é a prova decisiva para o valor do homem, e ainda, em resumo, para sua justificação existencial. “Quem não trabalha, não deve comer”. É possível apreciar quão perniciosa significação pode ter para o tipo melancólico a improdutividade forçada, por exemplo durante uma enfermidade. Também é óbvio, não obstante, que da coexistência da minuciosa "ordenalidade" com a elevada autoexigência pode se originar eventualmente um perigo: quando uma destas tendências se faz tão preponderante que a outra fica impedida de sua realização. Um aumento, ou também um impedimento, da exatidão ou minuciosidade diminui forçosamente o volume do trabalho, o qual, todavia, a nenhum preço deve se reduzir. Um aumento excessivo do quantum de trabalho traz consigo, forçosamente, um déficit de exatidão que se opõe à meticulosidade originária, aquela que às vezes, dentro de uma pura e acentuada unilateralidade, pode ampliar-se a uma síndrome obsessiva em toda regra e estorvar então a exigência de rendimento. Semelhante círculo de exaltação da autoexigência no rendimento, por um lado, e da minuciosidade, por outro, pode ser pernicioso e facilitar o desenvolvimento de uma depressão.

Este princípio restritivo da ordem é também o que se entrelaça nas relações inter-humanas. Estas vêm determinadas decisivamente por duas características: a primeira, o "ser-para-o-outro", em especial para o cônjuge e quase mais ainda para os filhos, tem a forma do "render-para-o-outro". A segunda, o modo de "ser-umcom-outro" é tão estreito, que muitas vezes não se pode designar senão como "simbiótico". Sempre é comovedor ver como aos olhos do tipo melancólico sua importância para o outro somente está no rendimento, nunca na existência simplesmente amorosa. O reverso da medalha é que quer ligar a família tão firmemente a si - tão simbioticamente firme - que se produz um vazio intolerável quando se afastam os membros da família, seja por matrimônio, separação ou morte. Esta procura se exerce profundamente sobre os filhos, assim como também a 


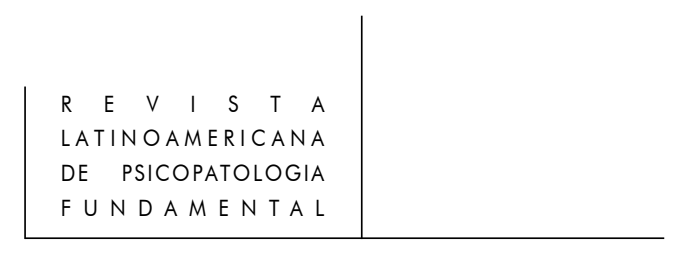

educação para o ideal melancólico de ordem, mas raramente provoca oposição, dado que nos filhos está reproduzida a mesma índole. Do que foi dito temos que, acima de tudo, são dois os momentos que podem ser perigosos a partir do "ser-com", do conviver: a impossibilidade de realizar a relação de domínio sobre o rendimento, sobretudo por estar enfermo ou envelhecer, e a solidão que significa o esvaziamento do âmbito, em que o direito mais profundo à existência está garantido pelo rendimento e pelos cuidados. O fato de que o próprio indivíduo possa chegar a ser um conteúdo desse campo é completamente estranho à natureza melancólica. Apresenta-se, então, um estancamento da existência que conduz às bordas do campo gravitativo da melancolia.

Se continuarmos, perguntando-nos agora de que forças ordenadoras está formada a relação do tipo melancólico consigo mesmo, veremos que se mostram, antes de tudo, segundo um modo específico de escrupulosidade. O depressivo revela uma extraordinária sensibilidade da consciência moral, de tal modo que a mesma tem perante tudo uma função proibitiva. Está atento a evitar toda culpa, por pequena que seja; e quando se vê carregado com alguma, esta é rapidamente anulada por uma conduta expiatória. A tendência a evitar culpas pode conduzir a expressões como esta: "Na verdade, eu nunca cometi uma falta". Muitas vezes pode-se supor que o tipo melancólico é radicalmente fariseu; mas desta maneira se expressa somente a angústia de cair na culpa. Para este tipo não existe sofrimento maior do que o de sentir-se sob pressão da culpa. Mas o mal é que ele mesmo amplia indevidamente sua possibilidade de chegar a ser culpável. Assim, por exemplo, observa-se em muitos depressivos uma notória intolerância com respeito à imputação de culpa por parte de outro, ainda quando esta seja injustificada. Que se lhes acuse de uma falta, faz neles amadurecer um peso, ao qual deve enfrentar-se energicamente a consciência moral. Mas, acima de tudo, considera como culpa o sentimento de não ter cumprido com o rendimento que ele mesmo havia se exigido. Dessa forma, a consciência depressiva é, em certo modo, uma consciência moral secularizada. O que em si é só um debet, passa a ter o mesmo peso que uma "culpa” para o depressivo. Inclusive no estado de saúde mostra-se, nessa sensibilidade à culpa, a possibilidade de uma compreensão para aquela vivência que depois, em forma e difusão grotescas, encontramos no delírio de culpa melancólico. Em todo caso, é facilmente imaginável como se pode desenvolver uma situação perigosa, quando o tipo predisposto a uma sensibilidade de culpa se vê exposto a uma carga séria da consciência moral. Em meu livro Melancholie ${ }^{24}$ cito uma série de exemplos sobre como se desenvolve em sequiência linear, uma melancolia de culpa a partir de tais situações. Que um homem seja organizado e escrupuloso deveria, com respeito à 


\section{CLÁSSICOS DA}

PSICOPATOLOGIA

sua saúde espiritual, alimentar mais esperanças que temor. Por isso nos perguntamos, ao final, que classe de "ordenalidade" é esta que evidentemente tem uma hierarquia tão decisiva para o surgimento de uma melancolia. Explicaremos isto detidamente no próximo tema ${ }^{25}$.

Sempre vemos como, praticamente desde o nascimento, este instinto de ordem é fomentado, favorecido e ainda cultivado por um dos pais igualmente predisposto. A criança pequena é, desde cedo, remetida a uma sujeição metódica, quando seria mais indicado prepará-la para uma disponibilidade ao mundo. Sabemos, pelos trabalhos psicanalíticos ${ }^{26}$, que tais influências do mundo vital da criança podem ser da maior importância. É facilmente imaginável que este mundo da "ordenalidade" pode chegar a ser também de importância patogênica, porque predispõe a encerrar o indivíduo dentro dos limites da "ordenalidade”. Ordem é aqui fixação e manutenção da vida entre limites rígidos, que dificilmente são transcendidos. Mas há momentos em que precisamente este transcender se faz necessário; quando situações adversas levam muito claramente à consciência da limitação do humano, e quando essas situações conduzem ad absurdum o planejar humano, e lhe impõem o risco do incerto. O próprio azar é um momento de "desordenalidade” na existência, e a culpa o é mais ainda. Por isso ambos são tão temidos pelo tipo melancólico.

Para a "ordenalidade" depressiva é inerente uma forma especial de desmedida. A ordem autêntica é sempre uma formação estruturada, uma combinação, perspectiva, proporção; aqui propagando-se além da estreiteza, lá desviando-se do excêntrico para o concêntrico; aqui derretendo o rígido, lá solidificando o demasiado fluido; aqui recuperando um atraso com o sacrifício do não essencial, lá postergando a permanência exclusiva no antecipar-se ao presente ativo; aqui substituindo o planejado com demasiada segurança por uma improvisação, lá conduzindo a vida fora da arbitrariedade do mero capricho, da fantasia, e levando-a ao trabalho severo frente ao objeto hostil, ao objetivo. Em outras palavras: aqui diástole, lá sístole. Em oposição a isto, o ameaçador toma corpo para o tipo melancólico no modo como ele vive a ordem, e a este modo de "ordenalidade" vai ligada incondicionalmente sua auto-realização. Não se sabe, contudo, como esta estrutura pode, em situações adequadas, conduzir a crises, e destas a modificações endógenas.

25. Aqui, Tellembach refere-se aos capítulos seguintes de onde este artigo foi retirado. (N. da T.) 26. Por exemplo, E.H. Erikson. Kindheit und Gesellschaft. Zurich-Stuttgart: Pan-Verlag, 1957. 